
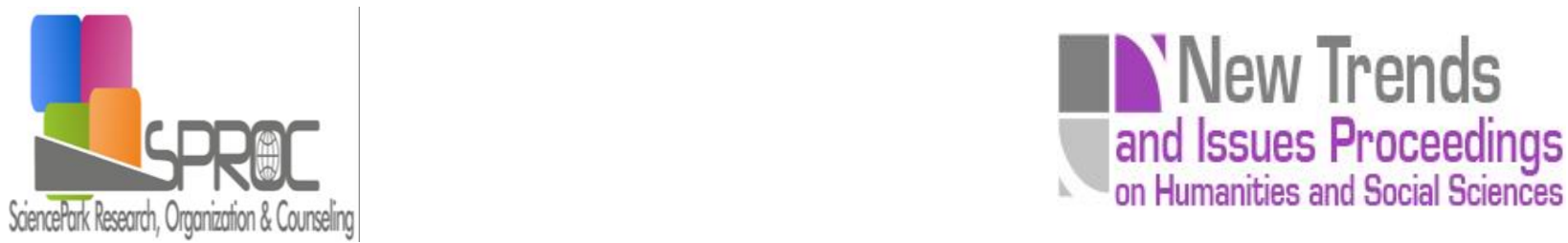

\title{
Communicative language in the virtual world
}

Begona Montero-Fleta *

Carmen Perez-Sabater ${ }^{b}$

Penny MacDonald ${ }^{c}$

Garcia-Carbonell $^{d}$

Andrea Conchado-Peiro ${ }^{e}$

Mervi Varhelahti ${ }^{f}$

Suggested Citation:

Abstract 
1. Introduction

2. Rationale of the study 
3. Methodology

Table 1. Question about formality in language use 

Table 1. Displays the strategies needed to be developed according to Finnish and Spanish employees

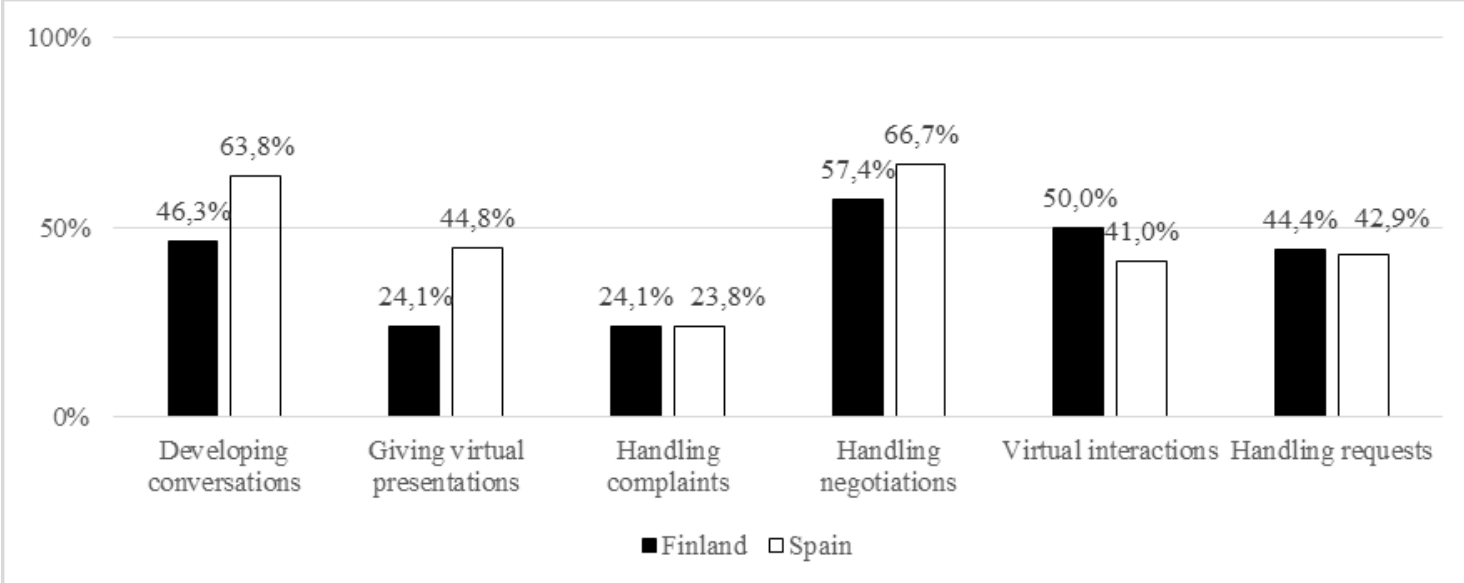




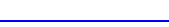


5. Implications for further research

Acknowledgements

References 


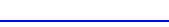

